NBER WORKING PAPER SERIES

\title{
EVALUATING MONETARY POLICY
}

Lars E.O. Svensson

Working Paper 15385

http://www.nber.org/papers/w15385

\author{
NATIONAL BUREAU OF ECONOMIC RESEARCH \\ 1050 Massachusetts Avenue \\ Cambridge, MA 02138 \\ September 2009
}

Prepared for Koenig, Evan, and Robert Leeson, eds., From the Great Moderation to the Great Deviation: A Round-Trip Journey Based on the Work of John B. Taylor, forthcoming. A first version of this paper was presented as a speech given at Uppsala University on March 13, 2009. I am grateful to Björn Andersson, Mikael Apel, Carl-Andreas Claussen, Paolo Giordani, Gabriela Guibourg, Tora Hammar, Neil Howe, Eric Leeper, Lina Majtorp, Mattias Villani, Staffan Viotti, and Anders Vredin for assistance and helpful comments. The views presented here are my own and not necessarily those of other members of the Riksbank's executive board or staff. The views expressed herein are those of the author(s) and do not necessarily reflect the views of the National Bureau of Economic Research.

NBER working papers are circulated for discussion and comment purposes. They have not been peerreviewed or been subject to the review by the NBER Board of Directors that accompanies official NBER publications.

(C) 2009 by Lars E.O. Svensson. All rights reserved. Short sections of text, not to exceed two paragraphs, may be quoted without explicit permission provided that full credit, including $@$ notice, is given to the source. 
Evaluating Monetary Policy

Lars E.O. Svensson

NBER Working Paper No. 15385

September 2009

JEL No. E52,E58

\begin{abstract}
$\underline{\text { ABSTRACT }}$
Evaluating inflation-targeting monetary policy is more complicated than checking whether inflation has been on target, because inflation control is imperfect and flexible inflation targeting means that deviations from target may be deliberate in order to stabilize the real economy. A modified Taylor curve, the forecast Taylor curve, showing the tradeoff between the variability of the inflation-gap and output-gap forecasts can be used to evaluate policy ex ante, that is, taking into account the information available at the time of the policy decisions, and even evaluate policy in real time. In particular, by plotting mean squared gaps of inflation and output-gap forecasts for alternative policy-rate paths, it may be examined whether policy has achieved an efficient stabilization of both inflation and the real economy and what relative weight on the stability of inflation and the real economy has effectively been applied. Ex ante evaluation may be more relevant than evaluation ex post, after the fact. Publication of the interest-rate path also allows the evaluation of its credibility and the effectiveness of the implementation of monetary policy.
\end{abstract}

Lars E.O. Svensson

Sveriges Riksbank

SE-103 37 Stockholm

Sweden

and NBER

lars.svensson@iies.su.se 


\section{Introduction}

In January 1999, a number of legislative changes came into force in Sweden that made the Riksbank more independent. As a result, the monetary policy decisions since then have been made by an Executive Board consisting of six members who are not permitted to seek or take instructions in the course of their work. These legislative changes can be seen as part of an international trend that has now been underway for a couple of decades - a trend towards an institutional framework for monetary policy with the aim of making monetary policy more effective and more able to promote both monetary stability and stability in the real economy.

This institutional framework for monetary policy rests on three pillars:

(1) A mandate for monetary policy from the government or parliament, normally to maintain price stability.

(2) Independence for the central bank to conduct monetary policy and fulfill the mandate.

(3) Accountability of the central bank for its policy and decisions.

The central bank's independence gives its governors a lot of power. In a democratic society, it is natural that the activities of the central bank are monitored and evaluated and that its independent management can be called to account. This contributes to maintaining the democratic legitimacy of the central bank. Accountability and regular evaluations of monetary policy also give the central bank stronger incentives to fulfill its mandate and motivate the central bank to develop its monetary policy analysis in the best possible way.

It also appears that detailed evaluations of monetary policy are becoming increasingly common. In Sweden, an annual evaluation is conducted by the Parliament's Committee on Finance, based on detailed material supplied and published by the Riksbank. An external and more comprehensive evaluation of ten years of Swedish monetary policy between 1995 and 2005 was carried out on behalf of the Committee on Finance by Francesco Giavazzi and Frederic Mishkin (Giavazzi and Mishkin 2006). The Committee on Finance has furthermore decided that Swedish monetary policy should now be evaluated by external experts every fourth year. On behalf of the Norwegian Ministry of Finance, an annual evaluation of monetary policy in Norway is carried out by Norges Bank Watch, a group of independent experts. I have taken part in two evaluations of monetary policy myself - an evaluation of ten years of monetary policy in New Zealand on behalf of the New Zealand Minister of Finance in 2001 (Svensson 2001) and an evaluation of monetary policy in Norway as Chairman of Norges Bank Watch in 2002 (Svensson, Houg, Solheim, and Steigum 2002).

Evaluations of monetary policy are important and appear to be becoming common practice. One must therefore ensure that reasonable principles and appropriate methods for evaluations are developed and applied. This is what I intend to discuss here. What should we consider when we evaluate monetary policy? What are the principles for a good evaluation of monetary policy and what is practically possible? How can principles and practice be developed compared with how evaluations are carried out today? Here I present a few suggestions for such development.

\section{Why not just examine whether inflation equals the target?}

An increasing number of central banks focus their monetary policy on achieving an explicit published inflation target. My discussion today will therefore be about evaluations of monetary policy with an explicit inflation target, inflation targeting. 
Given an announced inflation target, you may ask why an evaluation of monetary policy should be so complicated. When there is an inflation target, is it not simply enough to compare the actual outcome for inflation with the inflation target? There are at least two circumstances that make such an evaluation inadequate.

\section{Unanticipated shocks affect outcomes}

First, monetary policy does not provide complete control over inflation. A central bank is therefore unable to ensure that inflation will be exactly on target at every point in time. In fact, monetary policy is normally conducted under conditions of considerable uncertainty. The knowledge of the economic situation is not complete, and neither is the knowledge of how monetary policy affects inflation and the real economy, the so-called transmission mechanism of monetary policy. There is a considerable time lag before monetary policy measures have an impact on inflation, and the duration of this time lag also varies depending on the circumstances. The impact is normally gradual and becomes apparent over the course of a few years.

As monetary policy works with a time lag, it is most effective if it is based on forecasts. In order to achieve a given inflation target rate, it is therefore best to set the policy rate so that the inflation forecast a couple of years ahead equals the inflation target. However, during the time it takes for changes in the policy rate to have a full impact on inflation the economy will be affected by new and unexpected shocks. The inflation outcome a couple of years ahead will therefore have been affected by events that could not be predicted when the monetary policy decisions were made.

A direct comparison of outcomes and targets for inflation may therefore lead to the wrong conclusions. The inflation outcome may be in line with the target even if the monetary policy decisions were incorrect because the central bank was lucky and unexpected shocks nevertheless resulted in the right inflation outcome. Alternatively, the inflation outcome may deviate from the target even if the monetary policy decisions were correct because the central bank was unlucky and unexpected disruptions resulted in the wrong inflation outcome.

\section{Inflation targeting is flexible}

A second circumstance that means that a simple comparison of outcomes and targets for inflation is inadequate is that the Riksbank and all the other inflation-targeting central banks conduct flexible inflation targeting rather than strict inflation targeting. Flexible inflation targeting means that monetary policy aims at stabilizing both inflation around the inflation target and the real economy, whereas strict inflation targeting aims at stabilizing inflation only, without regard to the stability of the real economy, what Mervyn King (1997) has described as being an "inflation nutter". ${ }^{2}$

In many situations, a conflict may arise between stabilizing inflation and stabilizing the real economy. Let us assume that a shock, such as a sharp rise in the oil price, has driven up inflation at the same time as output has slackened significantly. If, in such a case, the aim of monetary policy is to quickly

\footnotetext{
${ }^{1}$ The terms "strict" and "flexible" inflation targeting were to my knowledge first introduced and defined in a paper of mine presented at a conference at the Bank of Portugal in 1996, later published as Svensson (1999). The term "inflation nutter" for a central bank that is only concerned about stabilizing inflation was introduced in a paper by Mervyn King at a conference in Gerzensee, Switzerland, in 1995, later published as King (1997).

${ }^{2}$ Heikensten and Vredin (2002) state that '[s]ince the mid 1990s, however, the Riksbank has explicitly declared that it is not a 'strict' but a 'flexible' inflation targeter (like most other central banks today)." They also clarify that this is consistent with the Riksbank's mandate: "This policy also has legal support. In the preparatory documents on [the law on] the Riksbank's independence it is said that the 'Riksbank, as an agency under the Riksdag, should accordingly have an obligation to support the general economic policy objectives to the extent that these do not conflict with the price stability objective'. The task of the Executive Board is thus to implement this notion of 'flexible' inflation targeting."
} 
bring inflation back to the target, a significant policy-rate increase may be required which will dampen output even further. By quickly stabilizing inflation - which would be the case with strict inflation targeting - the central bank would destabilize the real economy. By not aiming to bring inflation back to the target as quickly as possible, the central bank would help to stabilize the real economy. How long it should take to return inflation to the target depends, among other things, on the type, magnitude, and duration of the shock that has occurred and the importance that the central bank attaches to stability of the real economy.

A difference between the outcome and the target for inflation may thus be deliberate. It may be part of an appropriate compromise between stabilizing inflation and stabilizing the real economy. It is, therefore, simply not good enough to just compare outcomes and targets for inflation in an evaluation of monetary policy.

\section{What does flexible inflation targeting entail?}

Before I begin to discuss what evaluations of monetary policy should focus on, let me go into a little more detail about what characterizes flexible inflation targeting.

As I have already said, flexible inflation targeting entails the central bank striving to stabilize inflation around the inflation target and at the same time to stabilize the real economy. Stabilizing the real economy may be more precisely described as stabilizing resource utilization at a normal level.

There is an asymmetry between the impact of monetary policy on inflation and its impact on the real economy that it is very important to understand. Monetary policy can affect both the average level and the variability of inflation. Monetary policy cannot, on the other hand, affect the average level of real quantities such as output, employment, and resource utilization. Historically, attempts to use monetary policy to affect the average level of real variables such as employment and unemployment have led to serious mistakes and high inflation. In the case of the real economy, monetary policy can only affect, and to a certain extent dampen, fluctuations in real variables around their average levels. For monetary policy, it is thus meaningful to select a certain target for average inflation, but it is not meaningful and in fact counterproductive to select a certain target for average output or employment, other than the normal level that is determined by the workings of the economy and factors other than monetary policy.

Because of the lags between monetary-policy actions and the effect on inflation and the real economy, effective flexible inflation targeting has to rely on forecasts of inflation and the real economy. Flexible inflation targeting can be described as "forecast targeting". The central bank chooses an instrumentrate path so that the forecast of inflation and resource utilization "looks good." By a forecast that looks good I mean a forecast in which either inflation is already on target and resource utilization is already normal, or in which inflation is approaching the target and resource utilization is approaching a normal level at an appropriate pace. To be more precise, it means a forecast for inflation and resource utilization that as effectively as possible stabilizes inflation around the inflation target and resource utilization around its normal level and, in the event of conflicting objectives, achieves a reasonable compromise between inflation stability and resource utilization. Different central banks express this in slightly different words. The Riksbank has often used the term "a well-balanced monetary policy." 3

\footnotetext{
${ }^{3}$ The idea that inflation targeting implies that the inflation forecast can be seen as an intermediate target was introduced in King (1994). The term "inflation-forecast targeting" was introduced in Svensson (1997), and the term "forecast targeting" in Svensson (2005). See Svensson and Woodford (2005) and especially Woodford (2007a, b) for more discussion and analysis of forecast targeting.
} 
We can formalize and specify this reasoning somewhat by saying that it is a case of selecting a policyrate path that minimizes an intertemporal forecast loss function, written as the following standard quadratic form:

$$
\sum_{\tau=0}^{\infty} \delta^{\tau}\left(\pi_{t+\tau, t}-\pi^{*}\right)^{2}+\lambda \sum_{\tau=0}^{\infty} \delta^{\tau}\left(y_{t+\tau, t}-\bar{y}_{t+\tau, t}\right)^{2}
$$

Here, $\delta$ is a discount factor satisfying $0<\delta \leq 1, \pi_{t+\tau, t}$ denotes the mean forecast in quarter $t$ for inflation in quarter $t+\tau, \pi^{*}$ denotes the inflation target, $\lambda$ is a constant weight placed on the stabilization of resource utilization relative to the stabilization of inflation, $y_{t+\tau, t}$ denotes the mean forecast for (the logarithm of) output, and $\bar{y}_{t+\tau, t}$ denotes the mean forecast for (the logarithm of) potential output. The output gap $y_{t+\tau, t}-\bar{y}_{t+\tau, t}$ is thus used as a measure of resource utilization here. Let us call the difference between inflation and the inflation target the inflation gap. The sums of squares of the mean forecast gaps normally converge also for a discount factor equal to one. Let me for simplicity assume through the rest of the paper that the discount factor is equal to one. It is then a case of minimizing the sum of squares of the inflation-gap forecast, $\sum_{\tau=0}^{\infty}\left(\pi_{t+\tau, t}-\pi^{*}\right)^{2}$, plus the weight $\lambda$ times the sum of squares of the output-gap forecast, $\sum_{\tau=0}^{\infty}\left(y_{t+\tau, t}-\bar{y}_{t+\tau, t}\right)^{2} \cdot{ }^{4}$

\section{Evaluation ex ante - given the information available at the time of the decision}

So, given that a central bank conducts flexible inflation targeting, how should we evaluate the monetary policy the bank conducts? When evaluating monetary policy, as when evaluating decisions in general, we may adopt one of two different starting points. The first option is to base our evaluation on the information that is currently at hand; that is also including the information that has become available since the decision was made. This is, in other words, an evaluation after the fact. We can call this ex post evaluation. The second option is to put ourselves in the position of the decision makers at the time the decision was made and to try to evaluate the decision given the information that was then available. We can call this ex ante evaluation.

When evaluating monetary policy, the most interesting question is not whether the decision could have been better after the fact. As I said earlier, monetary policy is conducted under conditions of considerable uncertainty - there is a time lag before monetary policy has an impact on inflation and the real economy and the economy is constantly subject to new shocks. It is almost self-evident that monetary policy could have been better if the decision-makers had been aware when they made their decision that these shocks would happen. It is often equally self-evident that it was not possible to foresee the shocks at the time the decision was made. The relevant question is therefore primarily whether monetary policy could have been better given the information on the state of the economy and other factors that the central bank had access to when the decisions were made.

How then should an ex ante evaluation of monetary policy be carried out? I believe that we must take flexible inflation targeting seriously. For a central bank that conducts flexible inflation targeting it is

\footnotetext{
${ }^{4}$ The loss function should be minimised under commitment in a timeless perspective in order to ensure consistency over time of policy. The former Deputy Governor of Norges Bank, Jarle Bergo, has discussed this in a pedagogical manner in Bergo (2007). For a more technical approach see, for example, Woodford (2003), Svensson and Woodford (2005), Adolfson, Laséen, Lindé, and Svensson (2009), or Svensson (2009a).
} 
important, as I mentioned earlier, to choose a policy-rate path so that the forecast for inflation and resource utilization "looks good" in terms of stabilizing both inflation and the real economy and, in the event of conflicting objectives, entail a reasonable balance between stabilizing inflation and stabilizing the real economy. An ex ante evaluation should then aim to assess whether the central bank has succeeded in doing this.

Before making such an assessment of whether the central bank's forecasts look good, it is natural to first examine the general quality of the forecasts. Any assessment of the quality of the forecasts obviously entails an ex post analysis with the help of historical forecast errors. If the assessment is that the forecasts are of a reasonable quality it then becomes a question of assessing the monetary policy deliberations held on the basis of the forecasts the central bank makes. This primarily entails an ex ante analysis.

Obviously, the publication of central-bank forecasts of inflation and the real economy is a prerequisite for both an assessment of the forecasts' accuracy and whether they look good.

\section{Were the forecasts good enough?}

The first question we should ask is thus whether the central bank's forecasts are normally good enough. It would of course be going too far to demand that the central bank's forecasts should be perfect. As I have said, the economy is constantly subject to unexpected shocks, which means that the forecasts are always likely to be incorrect to some extent. Analyzing the accuracy of a forecast in an individual year thus provides limited information. A significant forecasting error may indicate that the forecast was poor, but it may also be due to the fact that a shock occurred that could not have been predicted. ${ }^{5}$

\section{Do the forecasts systematically over- or underestimate the actual outcomes?}

A reasonable requirement is that the forecasts for inflation, resource utilization, and so on do not systematically over- or underestimate the actual outcomes. In other words, the forecasts should not have any bias. If, for example, the forecasts for inflation over a long period of time on average over- or underestimate the actual inflation outcome, then this is a sign that there is information that the central bank is missing and that could be used to improve the forecasts. It is, however difficult to determine whether the forecasts are unbiased on the basis of a small number of outcomes.

\section{How do the central bank's forecasts compare with other forecasts?}

Another reasonable requirement is that the central bank's forecasts are on average not poorer than those of other forecasters. If the central bank's forecasts are systemically poorer than those of other forecasters, then this is obviously an indication that it would have been possible to make better assessments than those made by the central bank. This also means that better information was available which the central bank would have been able to use as a basis for its decision-making.

It is important to remember, however, that there are special conditions governing forecasting for a central bank that differ somewhat from those for many other forecasters. For the central bank it is not enough that the forecasts are accurate. This is one very important quality, but there are others. It must be possible, for example, to understand the driving forces behind the forecasts - why does the forecast look the way it does? How is the forecast affected by changes in assumptions regarding, for instance, demand abroad or the oil price? The central bank also needs a forecasting apparatus that can

\footnotetext{
${ }^{5}$ Uncertainty about and the revisions of GDP and other data make forecasting more difficult and also make it more difficult to evaluate the forecasts.
} 
effectively investigate the consequences of alternative monetary policies. For the Riksbank, which publishes its own interest-rate path, this is very important. To put it more technically, the central bank must use so-called structural models to assess the consequences of various policy-rate paths, while other forecasts can mainly be produced with the help of statistical models alone. Normally, there are good reasons for believing that structural models provide poorer forecasts than statistical models. However, the Riksbank's main structural model, Ramses, has very good forecasting properties (Adolfson, Laséen, Lindé, and Villani 2008).

When making historical comparisons between the forecasts of central banks and those of other forecasters, we also face a number of other difficulties. The first is that it is not certain that the central bank's forecasts are based on what the bank really believes is the best forecast of the policy rate and other variables. For a long time, the Riksbank, for example, based its forecasts on the assumption that the policy rate, the repo rate, would remain unchanged during the forecast period. Some central banks base their forecasts on both a constant policy rate and a constant exchange rate, which are often completely unrealistic assumptions. In such cases, the forecasts for inflation and the real economy are of course not the best forecasts. For a while, the Riksbank instead used the assumption that the reporate path would be given by the market's expectations of future repo rates. Although this is a more realistic assumption, it is not necessarily the same as the Riksbank's best forecast. These difficulties no longer apply to the Riksbank's forecasts as, since February 2007, the forecasts for inflation and the real economy are based on the Riksbank's best forecast for the future repo rate.

In order to arrive at a fair comparison of the forecasts of various forecasters, we should also take into account the fact that the forecasts are made at different times and are therefore based on different quantities of information. A forecaster that, for example, always publishes its forecasts later than other forecasters has generally more information on the economic situation when the forecasts are made. A comparison of the accuracy of the forecasts should therefore make adjustments for the forecasts being made at different times. Such an adjustment was included for the first time in a more systematic way in the material for the evaluation of monetary policy in the period 2006-2008 that the Riksbank published in February 2009 (Sveriges Riksbank 2009a).

Figures 1 and 2 show a comparison of the accuracy of the forecasts in the period 1999-2008 for CPI inflation and GDP growth for a number of forecasters. The red (darker for a black-and-white printer) bars show the absolute mean error adjusted for differences in publication dates. The blue (lighter) bars show the mean error with positive or negative sign. The shorter the blue bars, the smaller the systematic over- or underestimation has been - and the less bias the forecasts have had. If the bar is above the zero line the mean error has been positive and the forecasts have on average been too low, and vice versa. In the case of both inflation and GDP growth, the Riksbank's accuracy has been relatively good and its bias relatively small compared to other forecasters. 
Figure 1. Forecast errors for a number of forecasters 1999-2008, CPI inflation, percent

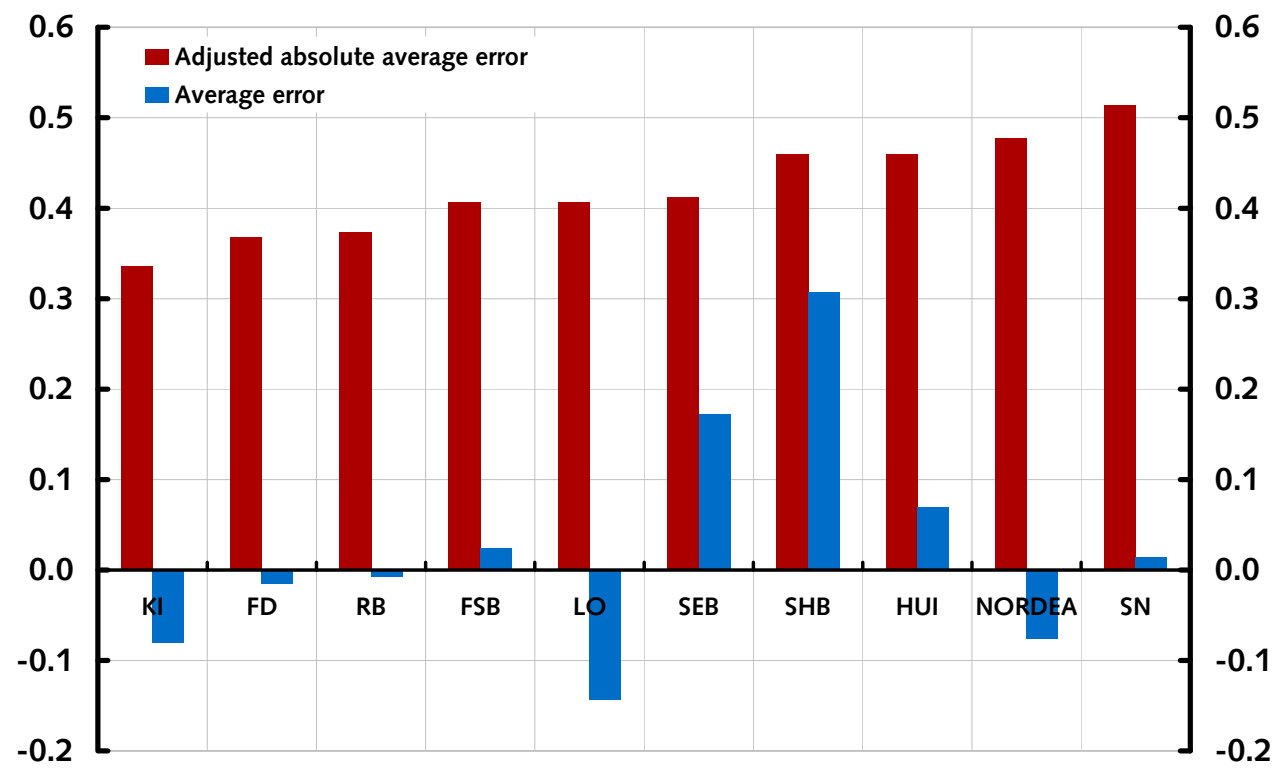

Sources: National Institute of Economic Research and the Riksbank. KI denotes the National Institute of Economic Research, FD the Ministry of Finance, RB the Riksbank, FSB Swedbank, LO the Swedish Trade Union Confederation, SHB the Svenska Handelsbanken, HUI the Swedish Retail Institute, and SN the Confederation of Swedish Enterprise.

Figure 2. Forecast errors for a number of forecasters 1999-2008, GDP growth, percent

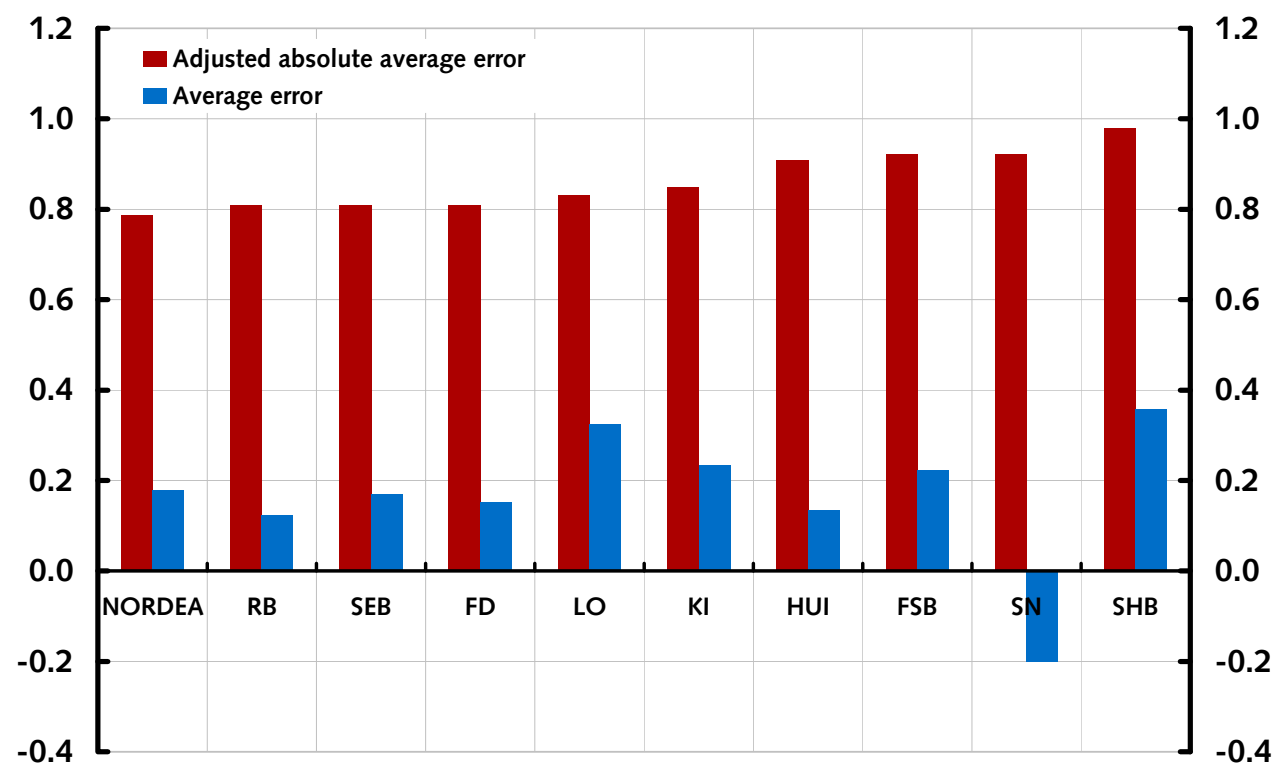

Sources: National Institute of Economic Research and the Riksbank. 


\section{Was monetary policy well-balanced ex ante?}

Given that it has been determined that the central bank's forecasts are normally satisfactory, the next step is to analyze, ex ante, the monetary policy deliberations the central bank has conducted on the basis of the forecasts.

\section{Was monetary policy efficient?}

The first question to answer is whether the monetary policy conducted has been efficient. Given the information available at the time the decision was made, would it have been possible, by selecting a different policy-rate path, to have stabilized inflation or the real economy better without stabilizing the other less well? Would it even have been possible to achieve a better stabilization of both?

The idea behind an efficient monetary policy can be illustrated using a modified Taylor curve. The original Taylor curve illustrates the efficient tradeoff between the unconditional variances of inflation and output (Taylor 1979). The modified Taylor curve, what I call the forecast Taylor curve, illustrates the efficient tradeoff between the conditional variability of the inflation- and output-gap forecasts. ${ }^{7}$

Figure 3. The forecast Taylor curve

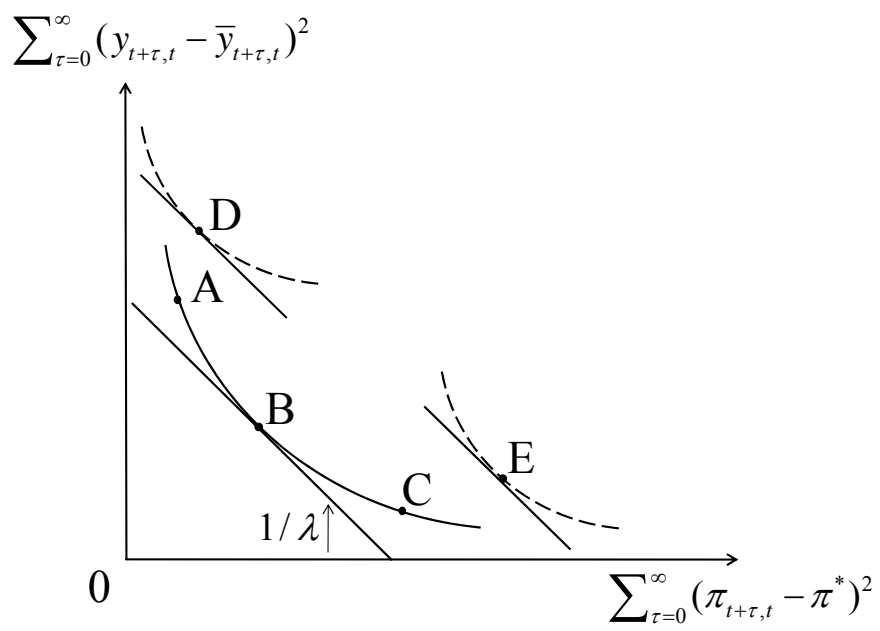

As I have said above, under flexible inflation targeting the central bank aims to stabilize inflation and resource utilization; that is to minimize the deviations from the inflation target and the normal level for resource utilization. In figure 3 , the sum of squares of the inflation-gap forecast is measured along the horizontal axis and the sum of squares of the output-gap forecast along the vertical axis. The curve through points $\mathrm{A}, \mathrm{B}$, and $\mathrm{C}$ is the forecast Taylor curve, that is, all the efficient combinations of forecasts for inflation and resource utilization, respectively, that it is possible to achieve in a certain decision-making situation with the help of different policy-rate paths. Points to the left and below the curve cannot be reached due to the initial state of the economy and the transmission mechanism

\footnotetext{
${ }^{6}$ Norges Bank has specified a few criteria for an appropriate interest-rate path that are reported in each issue of its Monetary Policy Report and were developed by Qvigstad (2006).

${ }^{7}$ The original figure in Taylor (1979) plotted the unconditional standard deviation of the output deviation from trend against the unconditional standard deviation of inflation. Svensson (2009a) provides more details on the forecast Taylor curve and shows how evaluation with the help of the forecast Taylor curves can be adjusted to take into account commitment in a timeless perspective, following Svensson and Woodford (2005).
} 
between inflation, resource utilization, and the policy rate. Points to the right and above the curve are inefficient in the sense that it is possible for monetary policy to achieve a smaller sum of squares of the inflation-gap forecast for a given sum of squares of the output-gap forecasts, or vice versa.

In its Monetary Policy Reports, the Riksbank usually presents alternative scenarios with a different repo-rate path in addition to the main scenario. These generate other paths for inflation and the output gap. Figures 4, 5, and 6 show examples from February 2008, February 2009, and July 2009. Panel a in each figure shows the alternative repo-rate paths (with "Main" denoting the majority decision and what is called the main scenario in the corresponding Monetary Policy Report or Update), panel b shows the corresponding inflation forecasts (the underlying CPI inflation measure CPIX is shown for February 2008 whereas CPIF, the CPI with housing costs calculated for a constant interest rate, is shown for February and July 2009), and panel d shows the corresponding output-gap forecasts (with the output gap measured as deviation from an HP trend). ${ }^{8}$

Panel c, labeled Variability tradeoffs, in figures 4-6 show the corresponding mean squared gaps, the average sums of squares of the inflation-gap and output-gap forecasts (calculated over the forecast horizon of normally 12 quarters). These mean squared gaps then illustrated the variability of the inflation-gap and output-gap forecasts and the tradeoff between them for different repo-rate paths, as for the forecast Taylor curve in figure $3 .^{9}$

Figure 4. Forecasts for the repo rate, inflation, and output gap and variability tradeoff, February 2008
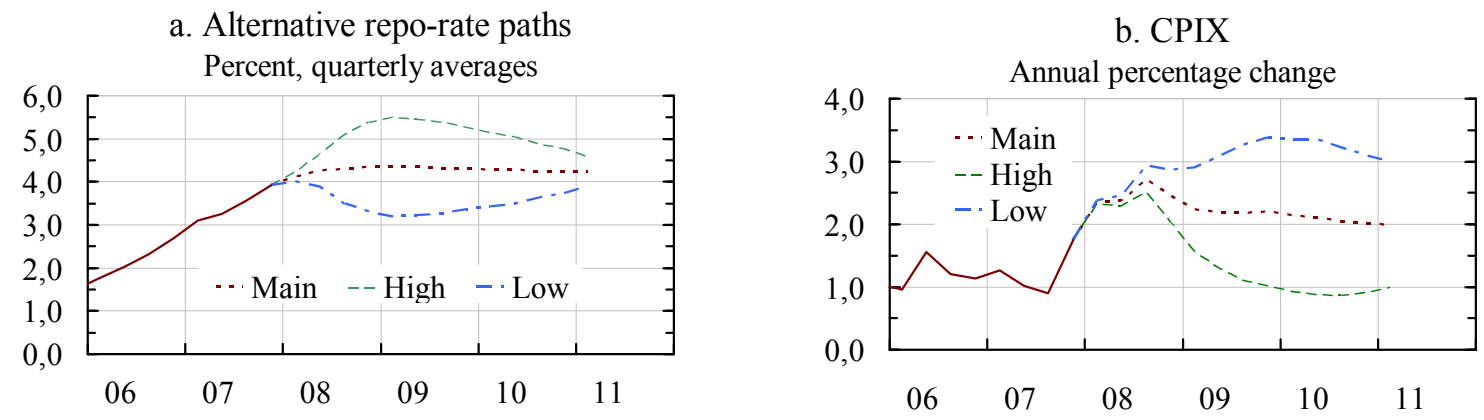

c. Variability tradeoffs
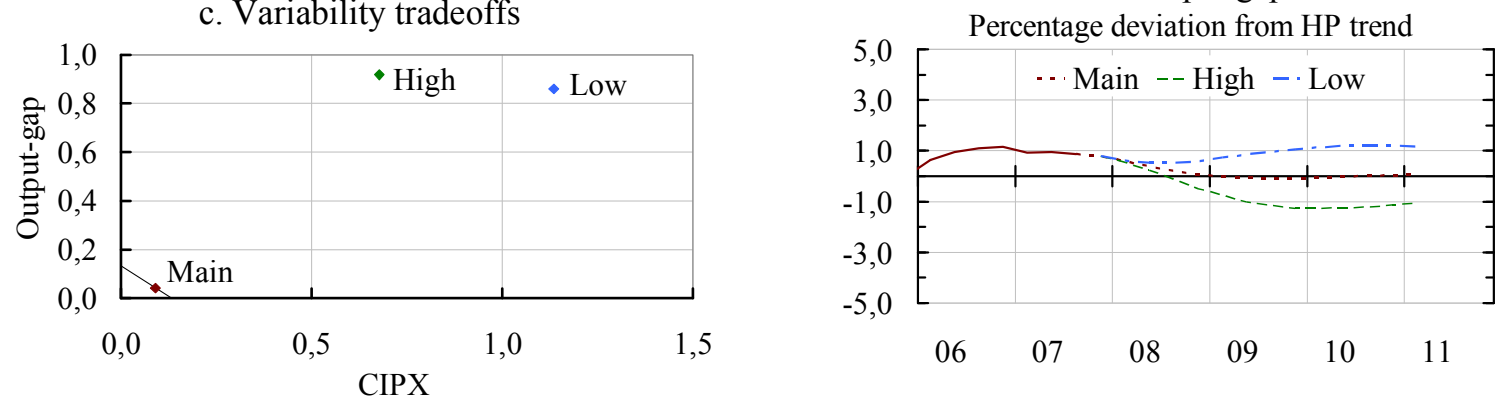

Sources: Statistics Sweden and the Riksbank

${ }^{8}$ The CPIX is a core inflation price index that excludes mortgage costs and effects of indirect taxes and subsidies. After June 2008, the Riksbank has downgraded the role of the CPIX and increased the emphasis on CPI. During 2009, when the policy rate has been adjusted in large steps, the interest-rate effects on the CPI have been large and the Riksbank has therefore increased the emphasis on the CPIF, the CPI adjusted for a constant interest rate (see Wickman-Parak 2008).

${ }^{9}$ The mean squared gaps for the inflation-gap and output-gap forecasts are calculated as $\sum_{t=0}^{T}\left(\pi_{t+\tau, t}-\pi^{*}\right)^{2} /(T+1)$ and $\sum_{\tau=0}^{T}\left(y_{t+\tau, t}-\bar{y}_{t+\tau, t}\right)^{2} /(T+1)$, where $\mathrm{T}$ is the forecast horizon (normally 12 quarters). 
Figure 5. Forecasts for the repo rate, inflation, and output gap and variability tradeoff, February 2009
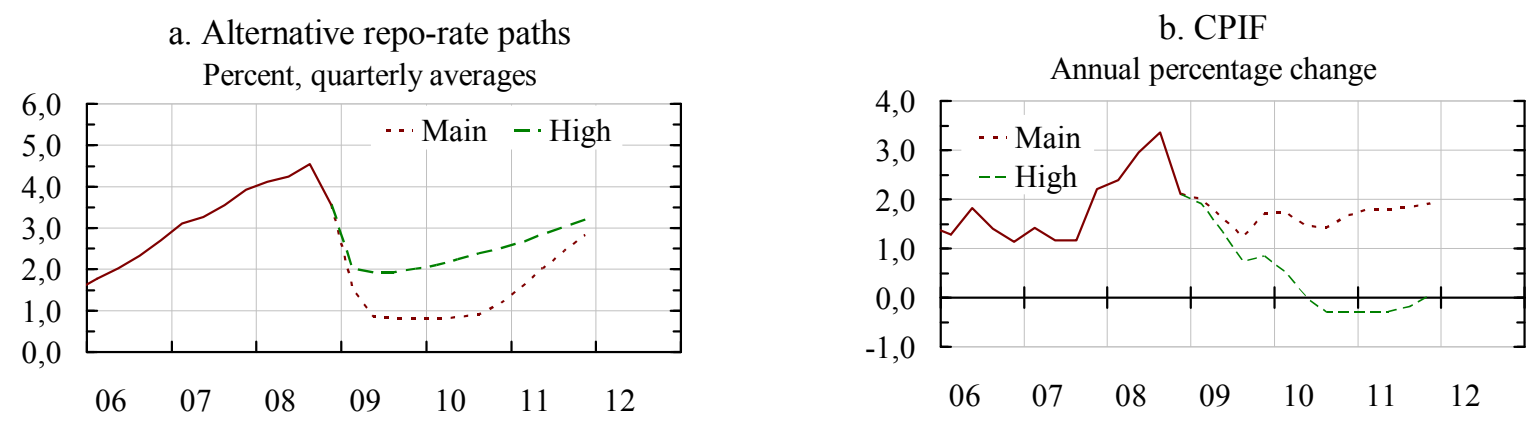

c. Variability tradeoffs

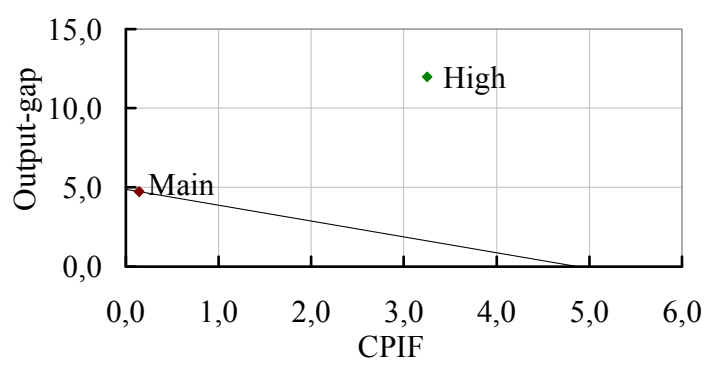

d. Output gap

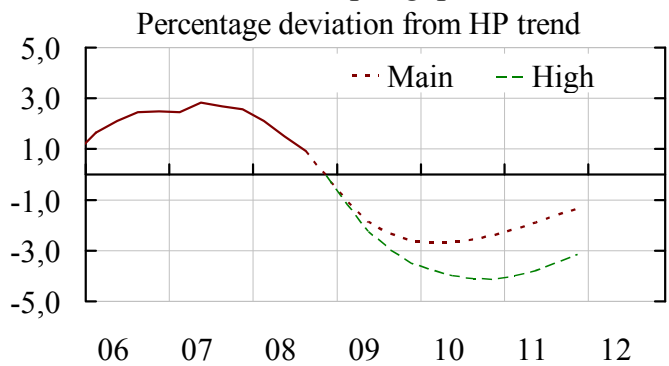

Sources: Statistics Sweden and the Riksbank

Figure 6. Forecasts for the repo rate, inflation, and output gap and variability tradeoff, July 2009

a. Alternative repo-rate paths

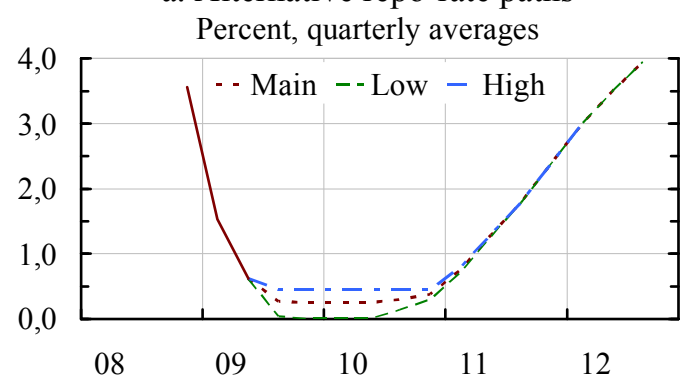

c. Variability tradeoffs

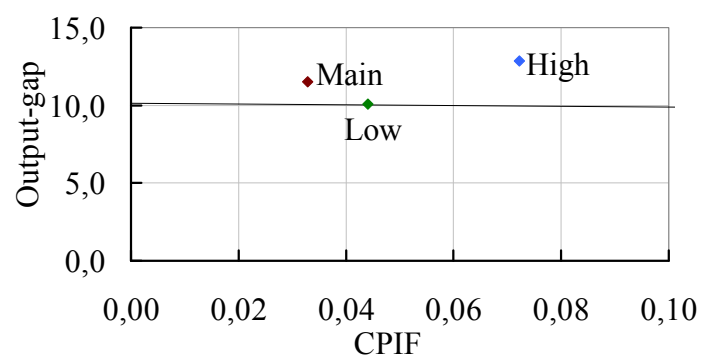

b. CPIF

Annual percentage change

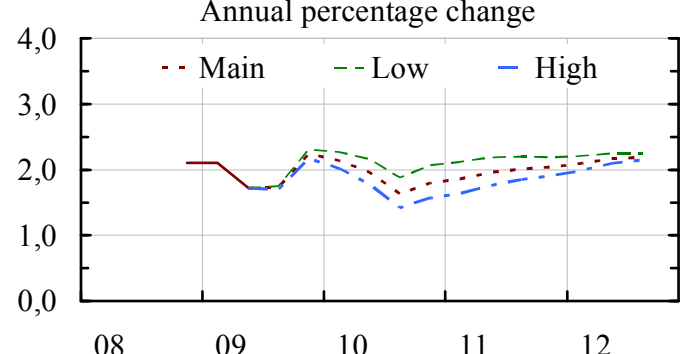

d. Output-gap

Percentage deviation from HP trend

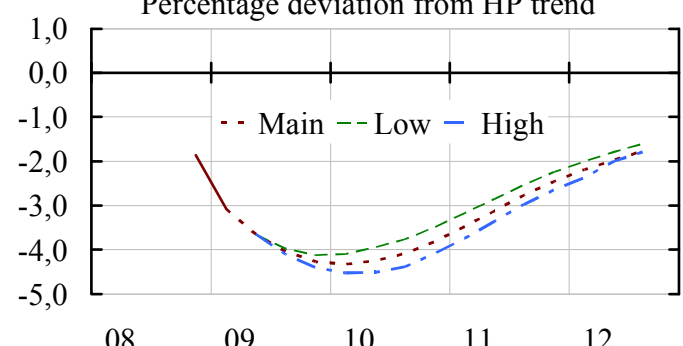

Sources: Statistics Sweden and the Riksbank

Figure 7 shows the variability tradeoffs from these examples in the same figure. Several observations can be made here. First, for February 2008 and 2009, the mean squared gaps for the main scenario are smaller than in the alternative scenarios; the main scenario is closer to the origin of the axes. The main 
scenario is thus more successful in terms of stabilizing both inflation and resource utilization. ${ }^{10}$ The alternative repo-rate paths are clearly inefficient compared with the main scenario. This does not necessarily mean, however, that monetary policy is efficient in the sense that the main scenario lies on the forecast Taylor curve. There may be a repo-rate path that would stabilize inflation and resource utilization even better. Excluding this possibility requires a comparison with many more alternative scenarios.

Figure 7. Variability tradeoffs: February 2008, February 2009, and July 2009.

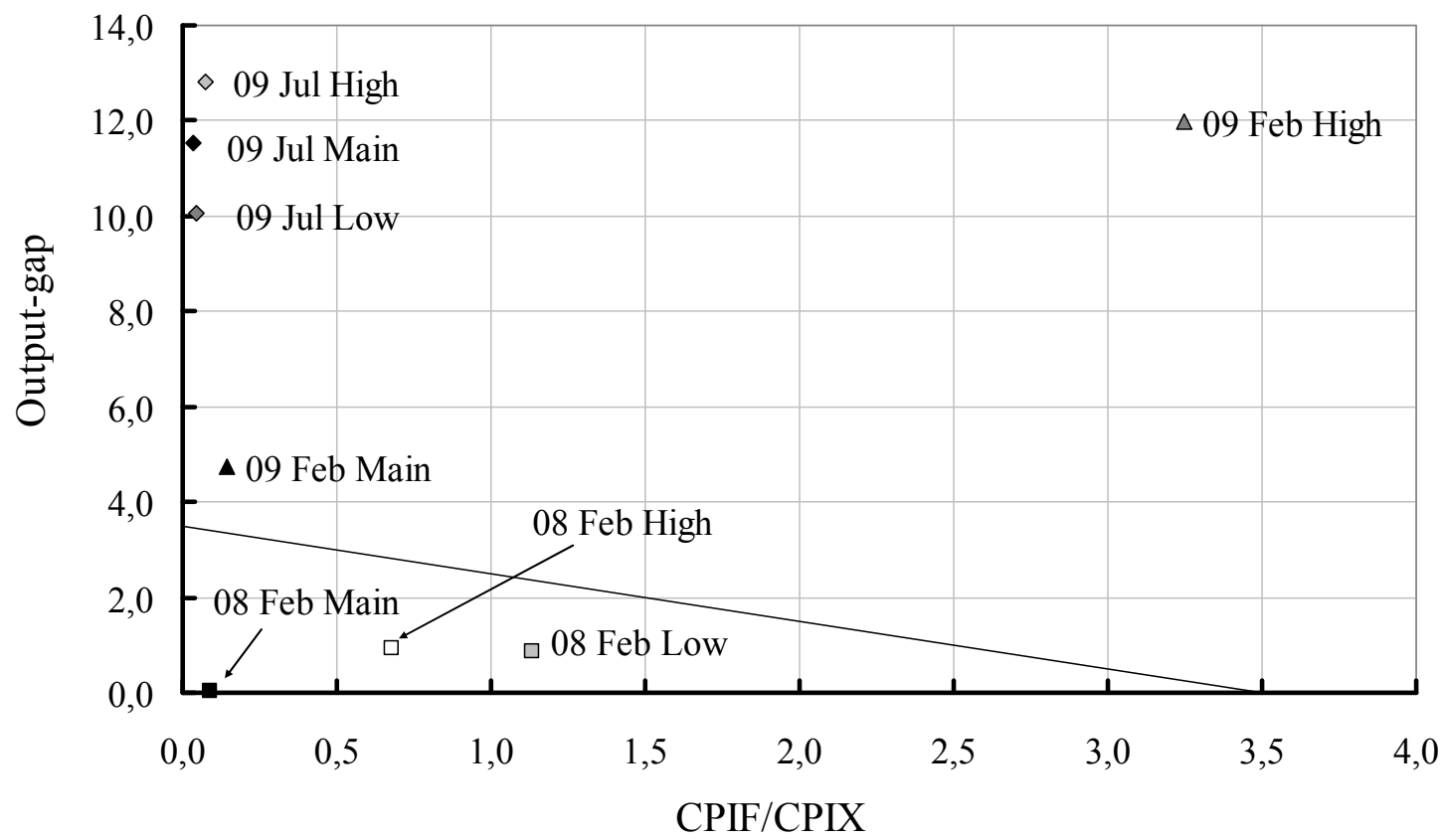

Sources: Statistics Sweden and the Riksbank

Second, for July 2009, the main and alternative repo-rate paths are very similar with regard to the degree of inflation-gap stabilization, although the main repo-rate path results in a slightly smaller mean squared gap for the inflation gap, as can be seen in panel $\mathrm{c}$ of figure 6 . However, the repo-rate paths result in different degrees of output-gap stabilization, where the low repo-rate path stabilizes the output-gap better and the high repo-rate path worse than the main scenario. The high repo-rate path results in an inefficient outcome with higher mean squared gaps for the inflation- and output-gap forecasts.

Third, the position of the forecast Taylor curve may vary considerably depending on the initial state of the economy. The situation in July 2009 was worse than that in February 2009, which was worse than that in February 2008. The point in figure 7 that corresponds to February 2008 is not far from the origin, while the points that correspond to February 2009 and July 2009 are much further away from the origin.

\footnotetext{
${ }^{10}$ I use expressions such as "stabilizing the inflation gap" and "stabilizing the inflation-gap forecast" interchangeably. The conditional variance of the future inflation gap equals the squared inflation-gap forecast plus the variance of the forecast errors, and the variance of the forecast errors is here considered exogenous.
} 
Assessing whether monetary policy has been efficient thus entails attempting to determine whether monetary policy has been on the forecast Taylor curve or not. The analysis is therefore ex ante, which means that the starting point is the central bank's forecast for inflation and resource utilization rather than the actual outcomes. In practice it is of course difficult to perform a more precise analysis, it becomes rather a question of determining to what extent monetary policy has been clearly inefficient in the sense that it is easy to find another policy-rate path that would stabilize inflation more without stabilizing resource utilization less, or that would even stabilize both more. A factor that can make the analysis even more complicated is if the central bank, apart from inflation and a measure of resource utilization, also includes other targets or limitations in its monetary policy deliberations. On such conceivable factor is so-called interest-rate smoothing, in other words that the central bank also chooses to even out the changes in the policy rate and ensure that they are made in relatively small and regular steps, for example by 0.25 percentage points at a time. With such a restriction, monetary policy will be located at a point above and to the right of the forecast Taylor curve. Alternatively, one can say that an additional axis and thus an additional dimension are required that correspond to the sum of squared changes in the policy rate, so that the forecast Taylor curve becomes a three-dimensional, bowl-shaped surface. A separate issue is whether there is any good reason for such implicit or explicit interest-rate smoothing. During the last year's dramatic events, several central banks have adjusted their policy rates in larger steps than usual, and it remains to be seen whether there will be less interest-rate smoothing during more normal times in the future.

A major difficulty in this analysis is that it may be unclear what is meant by stabilizing resource utilization around a normal level. The problem is that resource utilization can be measured in several ways. A reasonable and commonly used measure of resource utilization is the so-called output gap; that is the difference between actual output and potential output. However, potential output is not a magnitude that can be observed directly - it must be estimated. There is considerable uncertainty, both theoretically and empirically, about the best way to define, estimate, and forecast potential output. The output gap shown in the figures are output deviations from an HP trend, which has significant weaknesses. It is important and desirable from several points of view that the Riksbank and other central banks develop better measures of resource utilization and potential output and that they publish their measurements and forecasts. Such work is underway at the Riksbank.

\section{Was monetary policy well-balanced?}

Assuming, however, that we nevertheless conclude that monetary policy has not been clearly inefficient in the sense that I described earlier, the next step is to focus on what combination of the stabilization of inflation and the real economy the central bank actually selected or, in other words, which of all the possible points on the Taylor curve the central bank selected. There are many different efficient monetary policy alternatives to choose between every time a monetary policy decision is made. But did the central bank make a good choice? In the event of a conflict between stabilizing inflation and stabilizing the real economy, did the combination chosen by the central bank represent a reasonable balance between the two? Did the central bank attach reasonable importance to the stabilization of the real economy in relation to the stabilization of inflation?

In the literature, as in the case of the forecast loss function I presented earlier, the constant that is the relative weight that the central bank gives to the stabilization of the real economy in relation to the stabilization of inflation is often denoted by the Greek letter lambda, $\lambda$. In figure 3 , we can show the intertemporal forecast loss function with the help of isoloss curves for combinations of sums of squared inflation-gap and output-gap forecasts that generate equally large losses. Such isoloss curves are in this case downward-sloping, straight lines with a slope of $1 / \lambda$, the reciprocal of lambda. Isoloss lines closer to the origin correspond to lower losses. The ideal, but normally unattainable, situation 
would be an isoloss line at the origin, which represents a loss of zero and means that the forecast for inflation is exactly on target and that the forecast for resource utilization is exactly equal to the normal level. However, the forecast Taylor curve shows the minimum sums of squares that are possible on each decision-making occasion. The best monetary policy therefore entails selecting a point on the Taylor curve so that the isoloss line for the loss function is as close to the origin as possible. This is the point at which the isoloss line is a tangent to the Taylor curve. Figure 3 shows an isoloss line that is a tangent to the Taylor curve at point $\mathrm{B}$. For the given lambda, which determines the slope of the isoloss lines, this point thus represents a well-balanced monetary policy.

As I have emphasized, the position of the Taylor curve depends on the initial state of the economy at the time the decision is made. In a situation in which it is more difficult to stabilize resource utilization, the Taylor curve will be closer to the vertical axis than to the horizontal axis, for example like the dashed curve above point A. The point of tangency for an isoloss line with the same slope, which represents a well-balanced monetary policy, will then be at D. In a situation in which it is more difficult to stabilize inflation, the Taylor curve will instead be closer to the horizontal axis than to the vertical axis, for example like the dashed curve to the right of point $\mathrm{C}$. The point of tangency for an isoloss line with the same slope will then be at $\mathrm{E}$.

A central bank that has a low numerical value for lambda, that is a lower weight placed on the stability of the real economy, has steeper isoloss lines. For a central bank with such a lambda, the point of contact with a given Taylor curve for a given decision-making situation will be higher up to the left in the figure, for example at point A, where the Taylor curve is steeper. The inflation forecast will then be closer to the target, but the forecast for resource utilization will deviate more from the normal level. A central bank with a high numerical value for lambda, that is a high weight placed on the stability of the real economy, has isoloss lines that are flatter. In the case of such a lambda, the point of contact will be lower down to the left, for example at point $\mathrm{C}$, where the Taylor curve is flatter. The inflation forecast will then be further from the target while the forecast for resource utilization will be closer to a normal level.

Neither the Riksbank nor other central banks, except Norges Bank, have yet announced whether they apply a specific lambda and if so what this lambda is. ${ }^{11}$ In those cases where the decisions are made by a committee made up of several members, as at the Riksbank, it is possible that different members attach different degrees of importance to the stability of the real economy.

If the central bank's forecasts are only based on a known model, like the Riksbank's main model Ramses, it is possible to determine the position of the forecast Taylor curve and which point the Riksbank's main scenario in each Monetary Policy Report corresponds to. ${ }^{12}$ In practice, the Riksbank's forecasts and those of other central banks are based on several different models and a great deal of judgment. This means that it is not quite as easy to determine the position of the forecast Taylor curve. It is still possible, however, to enter the position of various forecast alternatives on the graph and at least assess whether the forecast is extreme in any respect with regard to the deviation of inflation from the target and the deviation of resource utilization from the normal level. As yet, it is in practice mainly a question of whether the choice of policy-rate path was extreme in either direction in the sense that the central bank gave considerable or very little relative weight to the stability of the real economy. Another interesting aspect to investigate is whether the weight attached to the stability of the

\footnotetext{
${ }^{11}$ Bergo (2007) and Holmsen, Qvigstad and Røisland (2007) report that optimal policy with $\lambda=0.3$ has replicated policy projections published by Norges Bank (with a discount factor of 0.99 and a weight on interest-rate smoothing of 0.2 ).

12 This can be done using the methods developed in Adolfson, Laséen, Lindé and Svensson (2009).
} 
real economy actually has been constant over time. If it has not been constant then the central bank's loss function has not been consistent over time, or it is more complicated than the quadratic loss function that I have discussed here and that is regarded as normal and reasonable in the literature on monetary policy.

As a reference point, I here use an equal weight on stability of the inflation and output gaps, that is a $\lambda$ equal to one. The solid negatively sloped lines in panel $\mathrm{c}$ of figures 4, 5, and 6 and in figure 7 hence show an isoloss line for a forecast loss function with equal weight on inflation- and output-gap stabilization.

As an example of the use of an equal weight, in the Bluebook for the Federal Reserve's FOMC meeting in May 2002 (Federal Reserve Board 2002) there is a description of a method involving what is arguably somewhat misleadingly called a "Perfect Foresight Policy" that minimizes an intertemporal forecast loss function with equal weight on inflation-gap and output-gap stabilization (and with a small weight on interest-rate smoothing). This method was used in the Bluebooks at the time to present policy alternatives for the FOMC. Svensson and Tetlow (2005) provide a detailed description of this method, which calculates optimal policy in the Federal Reserve's FRB/US model using information from the Greenbook forecast. They argue that "Optimal Policy Projections" is a better name, since perfect foresight need not be assumed. ${ }^{13}$

Figures 6 and 7 and the situation in July 2009 can be studied more closely in the light of this discussion. For July 2009, the main and alternative repo-rate paths are very similar with regard to the degree of inflation-gap stabilization, although the main repo-rate path results in a slightly smaller mean squared gap for the inflation gap, as can be seen in panel c of figure 6 . However, the repo-rate paths result in different degrees of output-gap stabilization, where the low repo-rate path stabilizes the output-gap better and the high repo-rate path worse than the main scenario.

For an equal weight on inflation- and output-gap stabilization the low repo-rate path results in lower intertemporal forecast loss. This is apparent from the isoloss line for $\lambda$ equal to one that is shown in both figures 6 and 7 (in figure 6 the isoloss line looks horizontal because the scales for the horizontal and vertical axes are so different). For the main repo-rate path to give a lower loss than the low reporate path, one needs a value of $\lambda$ lower than 0.08 .

At the policy meeting of July 2009, the main repo-rate path entailed lowering the repo rate from 50 basis points (from the April 2009 decision) to 25 basis points and keeping it there through 2010. The low repo-rate path entailed lowering the repo rate to zero. I dissented in favor of the low repo-rate path, on the grounds that it would entail a better-balanced monetary policy, with higher resource utilization and without inflation deviating too far from the target. The detailed discussion at the meeting is published in Riksbank (2009b), including arguments about the lower bound for the repo rate.

Finally, before I move on to discuss the evaluation of monetary policy after the event, I would like to emphasize that ex ante evaluations have the major advantage that they can be carried out on an ongoing basis in real time and that you do not need to wait several years to see the outcomes for inflation and the real economy. It is hence possible to evaluate whether monetary policy is wellbalanced currently, not only whether it was well-balanced in the past. If competent ex ante evaluations become a lasting feature of the ongoing public debate on monetary policy, they could constantly encourage the central banks to improve their policy and analysis.

\footnotetext{
${ }^{13}$ Bluebooks and other material from the FOMC meetings are published with a five-year lag and are available at www.federalreserve.gov.
} 


\section{Evaluation ex post - after the fact}

The most relevant starting point for an evaluation of monetary policy is, as I said earlier, the information and data that was available when the monetary policy decisions were made. That is an ex ante evaluation. However, an ex post analysis may also be relevant. The forecast evaluation that I discussed earlier was, for example, ex post. But an evaluation of monetary policy after the event can also provide valuable insights regarding the monetary policy conducted.

The question we should then ask is: given what we know today, what form would a better monetary policy have taken? Would it have been possible with a different monetary policy to achieve a better stabilization of resource utilization without undermining the stabilization of inflation, or vice versa? As this is an analysis in which we know what actually happened and what the results were, it is rather likely that we will discover that this would in fact have been possible. We would then have to get to the bottom of why such a monetary policy was not chosen. Could any of the outcomes have been predicted ex ante? Anyone may of course have luck with a single forecast. But was there another forecaster who in a convincing way actually predicted the shocks to the economy that occurred and that the central bank missed?

A large part of this analysis will thus concern evaluating and explaining forecast errors - even individual errors - and deviations from the central bank's targets. It is actually fairer to focus on forecast errors than deviations from targets, as deviations from targets under flexible inflation targeting may be deliberate on the part of the central bank.

Evaluating the central bank's forecasts is thus important; that is investigating whether the forecasts systematically over- or underestimate outcomes and so on. It is also interesting to compare forecast errors for inflation, for the real economy - irrespective of the measure of resource utilization used and for the policy rate if the central bank publishes such a forecast. Which forecast errors are most relevant for explaining why monetary policy, with the benefit of hindsight, could have been better? What were these forecast errors due to?

A disadvantage of an ex post evaluation is that we have to wait at least a couple of years for the outcomes for inflation and the real economy for the full impact of the monetary policy measures to become apparent. As I emphasized earlier, an ex ante evaluation can on the other hand be performed in real time as a part of the ongoing public debate on monetary policy.

\section{Was monetary policy credible?}

The credibility of monetary policy is always an important factor. The credibility of an inflationtargeting regime is usually measured by the proximity of private-sector inflation expectations for different time horizons to the inflation target. The closer the expectations are to the target, the higher the degree of credibility. This provides a direct indication of the private sector's level of confidence in the ability of the central bank to meet the inflation target.

Figure 8 shows how inflation expectations among money-market agents developed in 2008 and early 2009. It is evident that expectations for both one and two years ahead have been revised significantly downwards recently, which is hardly surprising given the development of the economy. For the fiveyear horizon, however, the expectations are well anchored around the target. 
Figure 8. Inflation expectations among money-market agents 1, 2, and 5 years ahead, 2008:Q1 to 2009:Q1

Annual percentage change

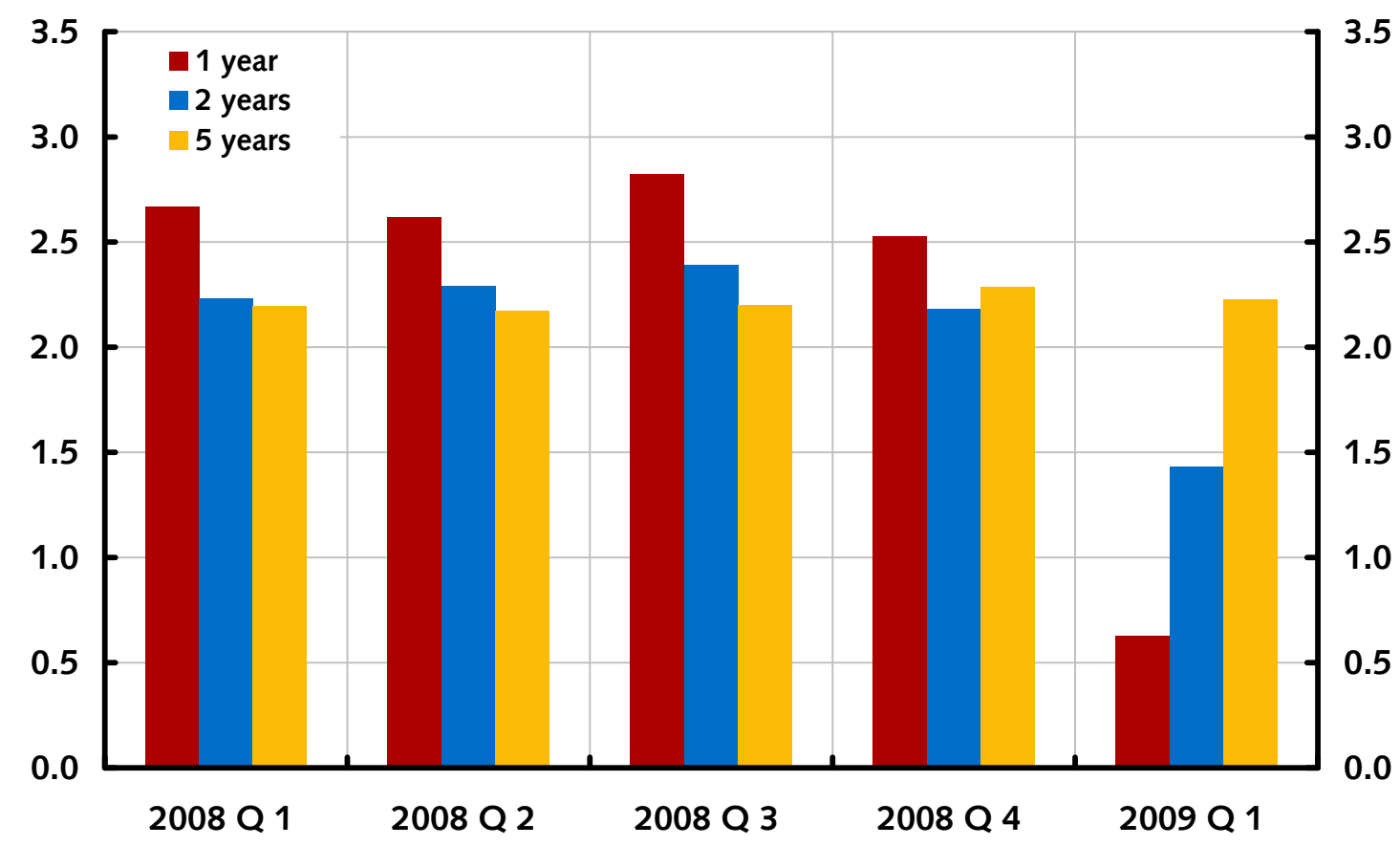

Sources: Prospera Research AB

How well inflation expectations are anchored around the target also has a direct impact on how well the central bank succeeds in meeting the target and on the possibilities the central bank has to also stabilize the real economy. This is because inflation expectations directly affect price and wage setting in the economy. Stable inflation expectations eliminate a potential source of shocks and make it easier for the central bank to stabilize both inflation and the real economy. More stable inflation expectations affect the transformation mechanism of monetary policy and shift the forecast Taylor curve in figure 3 closer to the origin and make the tradeoff between the stability of inflation and the stability of the real economy more favorable.

As the central bank's inflation forecasts in the short and medium terms may deliberately deviate from the target, it is also interesting to compare inflation expectations with the central bank's inflation forecasts. If the economic agents share the central bank's view of how inflation will approach the target, inflation expectations at different time horizons should be close to the central bank's forecasts. The degree of correspondence between inflation expectations and the central bank's inflation forecasts then becomes a measure of how credible the central bank's inflation forecasts and analyses are. Such a correspondence between expectations and forecasts is of course also desirable for forecasts for the real economy and, not least, for forecasts for the policy rate, which I will now discuss.

\section{Was the implementation of monetary policy effective?}

I have spoken earlier about what characterizes efficient monetary policy decisions. This was in relation to the tradeoff between stabilizing inflation and stabilizing the real economy given the information available at the time of the decision. Another important aspect is to investigate how effective the implementation of monetary policy has been, in the sense of affecting the economy in the desired 
direction and to the right amount. An effective implementation of monetary policy presupposes that there is a high level of private-sector confidence in the central bank with regard to both the inflation target and the monetary policy analysis. It also requires that the central bank is successful in communicating its analysis and intentions. In other words, a likely precondition for an effective monetary policy implementation is that the central bank is open and transparent.

Most central banks use a short-term interest rate as the policy rate to implement monetary policy. However, the actual policy rate in the few months prior to the next monetary policy decision plays a very minor role in the economy. Expectations regarding future policy rates, on the other hand, do play an important role. They affect interest rates with longer maturities which in turn are the interest rates that have an impact on the economic decisions of households and companies. The Riksbank and a few other central banks have taken this seriously and publish their own policy-rate paths to facilitate the formation of expectations regarding future policy rates and to influence these expectations more effectively. ${ }^{14}$

If the central bank is successful in its communication, the market participants should be able to predict rather well how new information or new shocks will affect the central bank's forecast for the policy rate. If the central bank's analysis is credible, the market's expectations regarding the future policy rate should also change in line with the revised policy-rate path of the central bank. One way of evaluating how effectively the central bank implements monetary policy is therefore to simply investigate how well the market participants have predicted the changes in the central bank's policy-rate path. We can also analyze how well the expectations regarding the future policy rate adapt to the central bank's new policy-rate path after the announcement. ${ }^{15}$ Figures 9 through 11 are examples of the type of figures that can be studied in this case. They relate to the policy decisions in June 2007, February 2009, and July 2009. The solid black line shows the actual repo-rate path, the dark dotted line shows the new reporate path, the light dotted line shows the previous repo-rate path, the yellow solid line shows market repo-rate expectations on the day before the announcement of the policy decision and the red solid line show the market expectations after the announcement. ${ }^{16}$ June 2007 and February 2009 show instances when the market both anticipated the repo-rate path reasonably well and when expectations after the announcements were reasonably well in line with the new path. As discussed in Svensson (2009c), this has mostly been the case since the Riksbank introduced its own repo-rate path in February 2007. However, July 2009 (and also April 2009, not shown here) are instances when market expectations before and after the announcement differed considerably from the announced path and expect higher future repo rates. On those instances, the Riksbank's implementation of monetary policy has hence been less effective. The reasons for and consequences of such differences between market expectations and the published repo-rate path are discussed in the July 2009 minutes (Sveriges Riksbank 2009b) and in Svensson (2009b).

\footnotetext{
${ }^{14}$ Woodford (2005) emphasizes the role of expectations in monetary policy and that monetary policy is largely the management of expectations.

${ }^{15}$ A preliminary analysis of the policy implementation from February 2007 through December 2008 is carried out in Svensson (2009c).

${ }^{16}$ Market expectations are implied forward-rate curves that have been adjusted by the staff for possible risk premia, so as to be the staff's best estimate of market expectations of future repo rates. Depending on the maturity, the forward-rate curve is derived from the rates for STINA (Tomorrow-Next Stibor interest-rate swaps) contracts, FRAs (Forward Rate Agreements), or interest-rate swaps.
} 
Figure 9. The Riksbank's repo rate path and market expectations, June 20, 2007

Percent

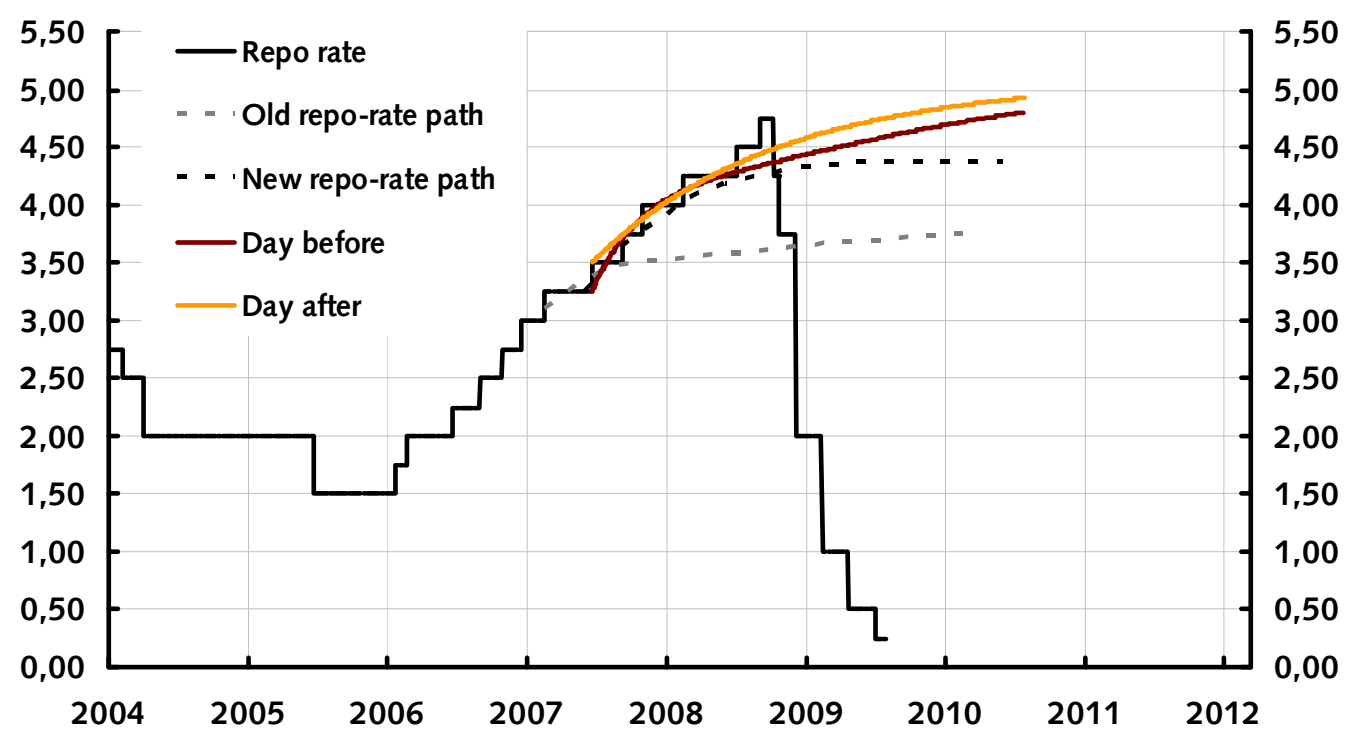

Source: The Riksbank

Figure 10. The Riksbank's repo rate path and market expectations, February 11, 2009

Percent

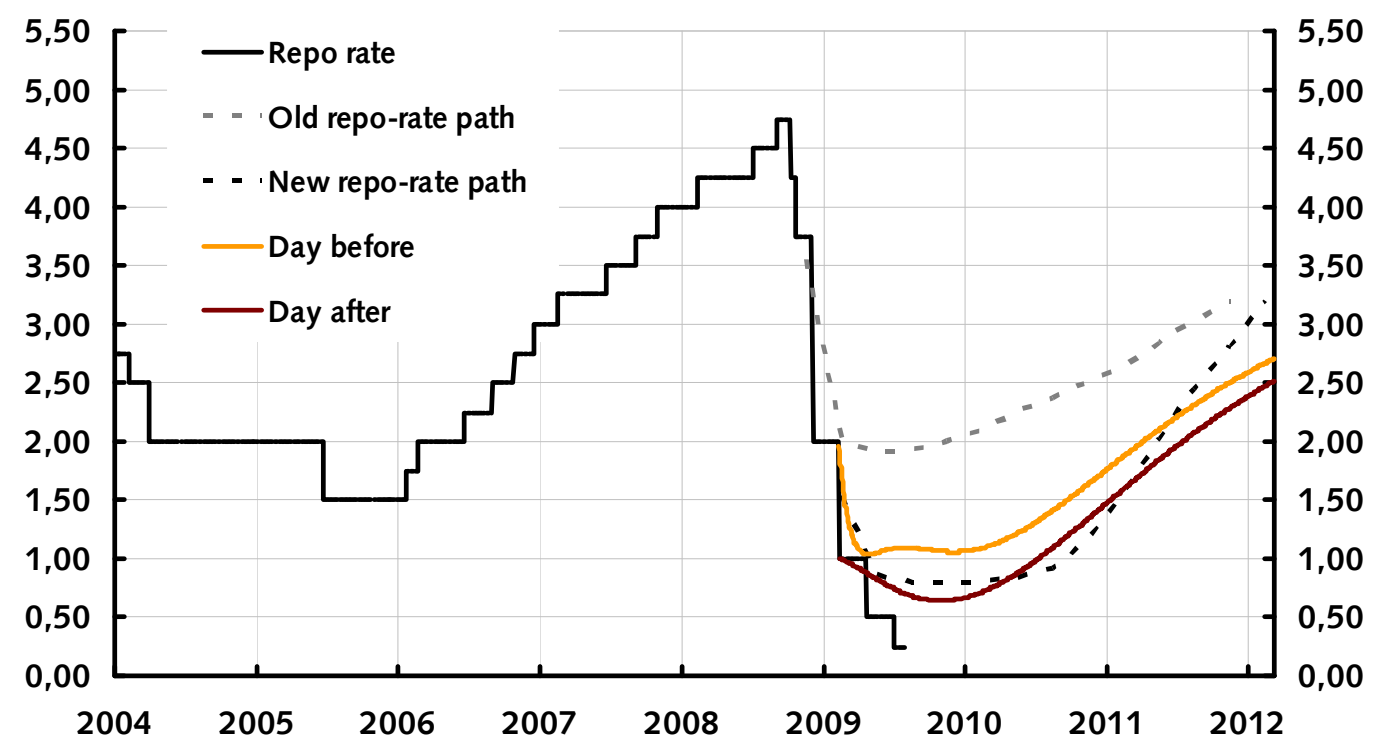

Source: The Riksbank 
Figure 11. The Riksbank's repo rate path and market expectations, July 2, 2009

Percent

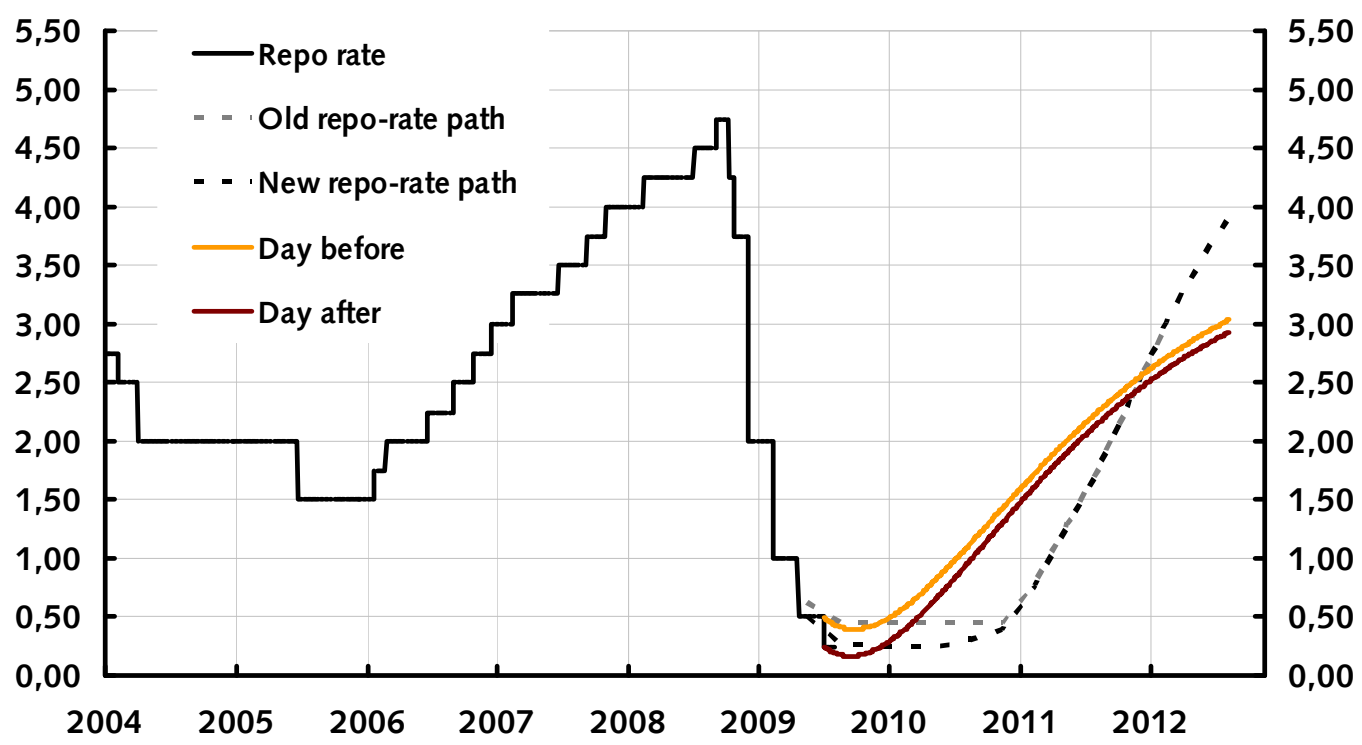

Source: The Riksbank

\section{Conclusions}

Let me conclude and sum up by first returning to the question I raised at the start: when evaluating monetary policy with an inflation target, why is it not enough to simply compare outcomes and targets for inflation? One reason is that inflation reacts with varying time lags and to different degrees to monetary policy measures. Inflation is also affected by shocks that are difficult to identify or that occur at a later date. The central bank does not therefore have complete control over inflation. Inflation can be on target even if the central bank has acted wrongly but been lucky, or deviate from the target even if the central bank has acted correctly but been unlucky. Another reason is that the Riksbank and other central banks with inflation targets conduct flexible inflation targeting, which means that they strive to both stabilize inflation around the inflation target and to stabilize the real economy. Inflation may then deliberately deviate from the target if this provides a better balance between stable inflation and a stable real economy.

As there is a significant time lag before monetary policy measures have an impact on inflation and the real economy, monetary policy is most effective when it is based on forecasts. With flexible inflation targeting, it is thus a question of choosing a policy-rate path so that the forecast for inflation and the real economy stabilizes inflation and the real economy as effectively as possible. It is thus possible and desirable to evaluate monetary policy ex ante and in real time by assessing to what extent the central bank's forecasts optimally stabilize both inflation and the real economy. However, before we do this it is necessary to assess whether the central bank's previous forecasts have been reasonably accurate and of good quality, for example in comparison with those of other forecasters.

With the help of a modified Taylor curve, a forecast Taylor curve that illustrates the efficient tradeoff between stabilizing the inflation forecast around the inflation target and stabilizing the resourceutilization forecast around a normal level, it is possible to evaluate ex ante and even in real time more precisely whether monetary policy is efficient and well-balanced. Forecast variability tradeoffs can be 
illustrated by plotting mean square gaps of inflation and output-gap forecasts for alternative policyrate paths.

It is also of interest to evaluate monetary policy ex post, that is, after the event. As target deviations and forecast deviations are unavoidable due to the considerable degree of uncertainty about the future development of the economy and the delayed impact of monetary policy measures, an ex post evaluation is mainly a question of whether it would have been possible to predict the shocks and deviations that occurred, particularly if other forecasters have systematically been able to predict them.

It is also relevant assess the credibility of monetary policy in terms of how well inflation expectations correspond to the inflation target. The degree of correspondence between expectations and the central bank's forecasts for inflation and the real economy is also a measure of the credibility of the central bank's analyses and forecasts.

As monetary policy is mainly about managing expectations, particularly expectations concerning future policy rates, it is of great interest to see to what extent a published policy-rate path has been predicted by the market and other forecasters. It is also interesting to know to what extent market expectations are adapted to the new policy-rate path. This can be seen as a measure of how effectively the central bank implements monetary policy.

\section{References}

Adolfson, Malin, Stefan Laséen, Jesper Lindé, and Lars E.O. Svensson (2009), "Optimal Monetary Policy in an Operational Medium-Sized DSGE Model," working paper, www.larseosvensson.net.

Adolfson, Malin, Stefan Laséen, Jesper Lindé, and Mattias Villani (2008), "Evaluating an Estimated New Keynesian Small Open Economy Model," Journal of Economic Dynamics and Control 32, 26902721.

Bergo, Jarle (2007), “Interest Rate Projections in Theory and Practice," speech on January 26, 2007, www.norges-bank.no.

Federal Reserve Board (2002), "Monetary Policy Alternatives," prepared for the FOMC meeting May 2, 2002, www.federalreserve.gov.

Heikensten, Lars, och Anders Vredin (2002), “The Art of Targeting Inflation,” Sveriges Riksbank Economic Review 4/2002, 5-34.

Holmsen, Amund, Jan F. Qvigstad and Øistein Røisland (2007), "Implementing and Communicating Optimal Monetary Policy,” Norges Bank Staff Memo No. 2007/3, www.norges-bank.no.

King, Mervyn (1994), "Monetary Policy in the UK,” Fiscal Studies 15(3), 109-128.

King, Mervyn (1997), "Changes in UK Monetary Policy: Rules and Discretion in Practice," Journal of Monetary Economics 39, 81-97.

Qvigstad, Jan F. (2006), "When does an interest rate path 'look good'? Criteria for an Appropriate Future Interest Rate Path,” Norges Bank Working Paper 2006/5.

Svensson, Lars E.O. (1997), "Inflation Forecast Targeting: Implementing and Monitoring Inflation Targets,” European Economic Review 41, 1111-1146. 
Svensson, Lars E.O. (1999), "Inflation Targeting: Some Extensions," Scandinavian Journal of Economics 101, 337-361.

Svensson, Lars E.O. (2001), "Independent Review of the Operation of Monetary Policy in New Zealand," report to the Minister of Finance, www.larseosvensson.net

Svensson, Lars E.O. (2005), "Monetary Policy with Judgment: Forecast Targeting," International Journal of Central Banking 1(1), 1-54.

Svensson, Lars E.O. (2009a), "Inflation Targeting," in Friedman, Benjamin M., and Michael Woodford, eds., Handbook of Monetary Economics, Volume 3a and 3b, North-Holland, forthcoming.

Svensson, Lars E.O. (2009b), "Policy Expectations and Policy Evaluations: The Role of Transparency and Communication," Sveriges Riksbank Economic Review, forthcoming, www.larseosvensson.net.

Svensson, Lars E. O. (2009c), "Transparency under Flexible Inflation Targeting: Experiences and Challenges,” Sveriges Riksbank Economic Review 1/2009, 5-44, www.riksbank.com.

Svensson, Lars E.O., Kjetil Houg, Haakon O.Aa. Solheim, and Erling Steigum (2002), “An Independent Review of Monetary Policy and Institutions in Norway," Norges Bank Watch 2002, www.larseosvensson.net.

Svensson, Lars E. O., and Robert J. Tetlow (2005), “Optimal Policy Projections,” International Journal of Central Banking 1(3), 177-207.

Svensson, Lars E.O. and Michael Woodford (2005), "Implementing Optimal Policy through InflationForecast Targeting," in Bernanke, Ben S., and Michael Woodford, eds. (2005), The InflationTargeting Debate, University of Chicago Press, 19-83.

Sveriges Riksbank (2009a), "Material for Assessing Monetary Policy 2006-2008,” February 2009, www.riksbank.com.

Sveriges Riksbank (2009b), "Minutes of the Executive Board's Monetary Policy Meeting on 1 July 2009," www.riksbank.com.

Taylor, John B. (1979), "Estimation and Control of a Macroeconomic Model with Rational Expectations," Econometrica 47, 1267-1286.

Wickman-Parak, Barbro (2008), “The Riksbank's Inflation Target,” speech on June 9, 2008, www.riksbank.com.

Woodford, Michael (2003), Interest and Prices: Foundations of a Theory of Monetary Policy, Princeton University Press.

Woodford, Michael (2005), "Central-Bank Communication and Policy Effectiveness," in The Greenspan Era: Lessons for the Future, Federal Reserve Bank of Kansas City.

Woodford, Michael (2007a), "The Case for Forecast Targeting as a Monetary Policy Strategy," Journal of Economic Perspectives, Fall 2007.

Woodford, Michael (2007b), "Forecast Targeting as a Monetary Policy Strategy: Policy Rules in Practice," in Koenig, Evan, and Robert Leeson, eds., From the Great Moderation to the Great Deviation: A Round-Trip Journey Based on the Work of John B. Taylor, forthcoming. 